FORMIGHIERI, A.P. et al. Adenocarcinoma nasal em cão: relato de caso. PUBVET, Londrina, V. 6, N. 5, Ed. 192, Art. 1289, 2012.

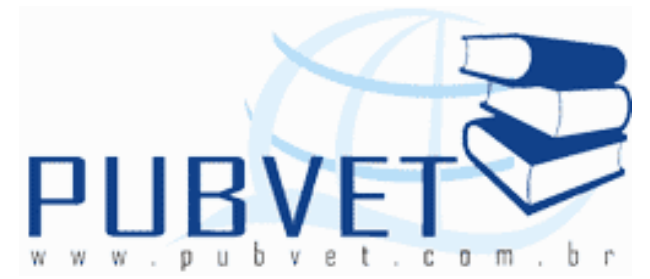

PUBVET, Publicações em Medicina Veterinária e Zootecnia.

\title{
Adenocarcinoma nasal em cão: relato de caso
}

Alice Pontes Formighieri ${ }^{1}$, Ana Claudia Cazarotto Cella ${ }^{1}$, Maysa Franzói de Carvalho $^{1}$, Liege Georgia Andrioli ${ }^{2}$, Andréa Christina Ferreira Meirelles ${ }^{2}$

${ }^{1}$ Acadêmico de Medicina Veterinária da PUCPR Campus Toledo. email: aliceformighieri@hotmail.com;

${ }^{2}$ Docente de Medicina Veterinária da PUCPR Campus Toledo.

\section{Resumo}

Estima-se que a incidência do câncer em cavidade nasal no cão seja de $1 \%$ de todos os cânceres e $80 \%$ dos tumores nasais são malignos. O tipo mais comum de câncer que afeta cavidade nasal em cães é o carcinoma, que inclui adenocarcinoma nasal. Há uma maior prevalência de neoplasias nasais em cães machos, principalmente raças dolicocéfalas e mesocéfalas assim como raças de grande porte. Os sinais clínicos do adenocarcinoma nasal são os mesmo das rinites infecciosas, incluindo corrimentos nasais catarrais ou mucopurolento, hemorragia periódica, lacrimejamento aumentado devido a obstrução dos ductos nasolacrimais e espirros, sendo muito importante o diagnóstico diferencial de rinite. Neoplasias grandes também interferem com o fluxo do ar causando respiração estertorosa. O presente trabalho relata um caso que foi encaminhado ao Hospital Veterinário da Pontifícia Universidade Católica do Paraná, Campus Toledo (PUC-PR), um cão da raça poodle, fêmea com cinco anos de idade, 3,6kg, com histórico de dispnéia inspiratória, 
FORMIGHIERI, A.P. et al. Adenocarcinoma nasal em cão: relato de caso. PUBVET, Londrina, V. 6, N. 5, Ed. 192, Art. 1289, 2012.

respiração estertorosa e secreção nasal mucopurolenta. Foram realizados exames radiológicos e citológicos sendo compatível com diagnóstico de adenocarcinoma nasal.

Palavras-chave: neoplasia; cão; cavidade nasal

\section{Introdução}

As neoplasias nasais podem originar-se de qualquer um dos tecidos que formam estruturas incluindo osso, cartilagem, tecido conjuntivo, vasos sanguíneos e todos os diferentes tipos de células das glândulas e do epitélio de revestimento nasal (adenoma ou carcinoma) $(1,2)$. As neoplasias nasais benignas são raras. Diferentemente, as malignas são mais comuns e geralmente maiores e com variação maior no tamanho, comparada as neoplasias benignas. Caracterizam-se, freqüentemente, por massas claras e mutilobuladas compostas de tecido sólido e friável, também, são localmente invasivas e tendem a infiltrar nos seios, cérebro, nervos e vasos, resultando em processo hemorrágico $(1,2,3)$. Os cães mais comumente acometidos são de raça grande, focinho longilíneo, sendo que o local mais afetado são os seios paranasais $(1,4)$. Estima-se que a incidência do câncer em cavidade nasal no cão seja de $1 \%$ de todos os cânceres e $80 \%$ dos tumores nasais são malignos, enquanto que nos gatos $92 \%$ dos tumores nasais são malignos. 0 tipo mais comum de câncer que afeta cavidade nasal em cães é o carcinoma, que inclui adenocarcinoma nasal, carcinoma de células escamosas e carcinoma indiferenciado $(5,6)$. O presente trabalho tem como objetivo relatar um caso de adenocarcinoma nasal encaminhado ao HV da PUC-PR ocorrido em cão.

\section{Materiais e métodos}

Um cão da raça poodle, fêmea com cinco anos de idade, $3,6 \mathrm{~kg}$, foi encaminhado ao Hospital Veterinário da Pontifícia Universidade Católica do Paraná, Campus Toledo (PUC-PR), em maio de 2011, com histórico de dispnéia inspiratória, respiração estertorosa e secreção nasal mucopurolenta. Foi realizada a rinoscopia em busca de alterações visíveis na mucosa, foi coletado 
FORMIGHIERI, A.P. et al. Adenocarcinoma nasal em cão: relato de caso. PUBVET, Londrina, V. 6, N. 5, Ed. 192, Art. 1289, 2012.

material para exame microbiológico de cultura fúngica e bacteriana no intuito de descartar estas infeç̧ões e radiografia. Também foi feito um lavado nasal e o conteúdo avaliado por exame citológico, com o objetivo de excluir a suspeita de tumor venéreo transmissível.

\section{Resultados e discussão}

O diagnóstico deve ser diferenciado de outras afecções da cavidade nasal, como rinites micóticas causadas comumente por Aspergillus spp e Penicilluim spp., parasitária por Pneumonyssus caninum e ainda as alérgicas (1). A rinoscopia mostrou presença de lesão hiperêmica, com abundante secreção nasal. O exame microbiológico foi negativo para cultura fúngica e bacteriana. Após uma semana o paciente apresentou deformidade facial na região dorsal do nariz, segundo a literatura algumas neoplasias podem infiltrar estruturas adjacentes e produzir deformidades faciais notáveis, perda de dentes, exoftalmia e sinais de distúrbios nervosos $(1,3)$.

No exame radiográfico, o espaço nasal apresentou-se com densidade assimétrica do lado esquerdo, apresentando áreas heterogêneas e radiopacidade água (Figura 1 ). Na passagem da sonda nasogástrica observouse estreitamento do canal nasal impedindo a passagem da sonda.

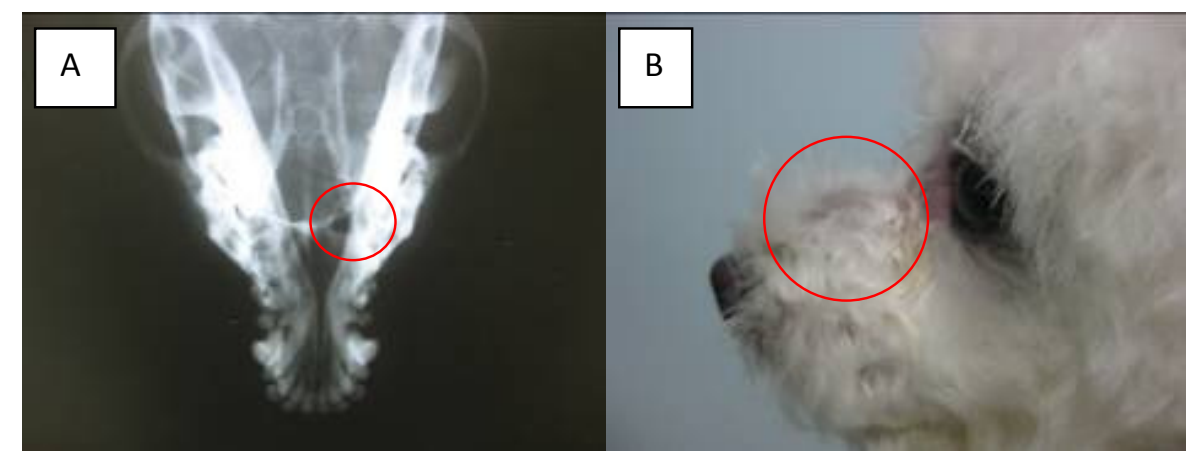

Figura 1 - A) Radiografia em projeção rosto-ventral indicando alteração no seio paranasal esquerdo. B) Aumento do volume na região dorsal do plano nasal, com início de deformidade facial. 
FORMIGHIERI, A.P. et al. Adenocarcinoma nasal em cão: relato de caso. PUBVET, Londrina, V. 6, N. 5, Ed. 192, Art. 1289, 2012.

Em relação à predisposição da doença, a literatura relata que os animais mais comumente afetados têm em média 10 anos de idade, são de porte grande com ligeira predileção de machos $(1,3,4)$. O caso clinico relatado, porem, trata-se de um cão, fêmea, de porte pequeno, com 5 anos de idade. Os sinais clínicos encontrados no paciente foram condizentes com a literatura que descreve ser freqüente o aparecimento dos mesmos sinais das rinites infecciosas, incluindo corrimentos nasais catarrais ou mucopurolentos, hemorragia periódica, lacrimejamento aumentado devido a obstrução dos ductos nasolacrimais e espirros. Neoplasias grandes interferem com o fluxo do ar causando respiração estertorosa $(1,2,7)$, o que também foi observado no caso aqui apresentado.

No exame citológico do tumor foi descartado a opção de tumor venéreo transmissível, entretanto, foi útil para confirmação do diagnóstico de Adenocarcinoma nasal, pois, o laudo descreveu células diferenciadas de padrão glandular, múltiplos focos com camadas coesivas de células, demonstrando um pleomorfismo moderado, com citoplasma intensamente vacuolizados e formato poligonal. O que concorda com a literatura pesquisada (1).

Nas neoplasias benignas o tratamento é principalmente direcionado ao controle local da doença, a massa tumoral pode ser removida cirurgicamente sem necessidade de outros tratamentos associados, porém, deve-se levar em consideração sua proximidade a órgãos como o cérebro e os olhos, o que restringe as opções de tratamento e complica o manejo do animal (3). As neoplasias benignas podem ser removidas cirurgicamente e não há necessidade de outros tratamentos associados. Já as malignas, requerem a remoção cirúrgica total do tumor, associada à radioterapia ou à quimioterapia, ou as duas últimas isoladamente (3).

Durante 15 dias o animal fez uso de um medicamento à base de solução fisiológica e cloreto de benzalcônio, então ao receber o diagnóstico de adenocarcinoma o proprietário optou por não tratar o animal. Até o presente momento sabe-se que o tumor continua progredindo. 
FORMIGHIERI, A.P. et al. Adenocarcinoma nasal em cão: relato de caso. PUBVET, Londrina, V. 6, N. 5, Ed. 192, Art. 1289, 2012.

\section{Conclusão}

Embora as estatísticas quanto ao sexo, idade, e raça do diagnóstico de adenocarcinoma nasal não coincidam com o caso aqui relatado, os sinais clínicos são indicativos do mesmo e isto está apoiado na investigação da origem do problema e nos exames complementares realizados que são fundamentais para o diagnóstico definitivo da doença.

\section{Referências}

1. Carlton WW; Mcgavin MD. Patologia Veterinária especial de Thomson. $2 \square$ ed. Porto Alegre: RS; 1998.

2. Silva CC; Scopel D; Sprandel L; Nunes FC; Fortes TP; Silva FS; Vives PS. Adenocarcinoma nasal em cão: relato de caso. XVIII Congresso de Iniciação Científica, XI Encontro de PósGraduação, I Mostra Científica; 2009 out. 20-23; Universidade Federal de Pelotas. Rio Grande do Sul.

3. Morris J; Dobson J. Oncologia em pequenos animais. 5 $\square$ ed. São Paulo: SP; 2007.

4. Messias MS. Tumores nasosinusais em cães. [Dissertação de Mestrado]. Lisboa: Universidade Técnica de Lisboa, 2008.

5. Degner AD. Nasal Cavity Tumors. ACVS Veterinary Surgeon [periódico on line] 2004; Disponível em: URL: http://www.vetsurgerycentral.com/oncology_nasal_tumors.htm [2011, maio. 8].

6. Birchard SJ; Sherding RG. Manual Saunders: Clínica de pequenos animais. São Paulo: SP; 1998.

7. Forrester SD \& Noftsinger. Abordagem inicial em cães com descarga nasal. Veterinary Medicine, 2002. 